\title{
SÕNA
}

\section{ÜKS LÕPUNI VIIDUD ETÜMOLOOGIA: KASIMA JA KASIN}

\author{
LEMBIT VABA
}

$\mathrm{V}$ erb kasima ja sellega tuletussuhtes olev kasin on üpris tavalised eesti keele sõnad, kuuludes üsna ulatusliku tuletushargmiku ja tähendusväljaga kümne tuhande sagedama sõna hulka (Kaalep, Muischnek 2002: 47). Julius Mägiste on EEW-s (3: 722-723) osutanud, et ee kasimaperel on vasteid liivi ja vadja keeles, ning märkinud, et kõne all on võib-olla (ev[en]t[uel]l) balti laen, laenualust siiski osutamata.

Seletav sõnaraamat avab nende semantika nii: kasima '(pesemise, pühkimise, harimisega) mustusest, tolmust, porist puhastama, koristama; kõnek. (hrl järsult käskides:) (ära) minema, lahkuma'; kasin : kasina 'vähene, vähesevõitu, napp; kõlbeliselt puhas, vooruslik, karske; vähenõudlik' (EKSS 2: 135). Murdesõnaraamatus on kasima 'puhastama, koristama, harima; veise järelsünnitusest, puhastusest: Juu ei ma 'enne lüpsa kedagi, kui ta [lehm] juba ennast ää kasind on; vilja või heina kokku panema, koristama' ja $\mathrm{R}$ eP kasin, eL kassin jt 'vähene, napp; kehv, vilets; väike; puhas, korralik, tubli' (EMS II/9: 801). Wiedemanni sõnaraamat (1973) esitab kasima tähendusnüansi 'millegi või kellegi eest hoolitsema, hoolt kandma / besorgen, Sorge tragen für etwas'. Andrus Saareste „Eesti keele mõisteline sõnaraamat” (EKMS) toob esile sõnade kasima ja kasin rahvakeelest ja kirjandusest põimitud tähendusi ja tähendusvarjundeid: kasima on esitatud mõisterühmades HOOLITSEMA (1: 517); MINEMA (2: 895) 'ära minema' fam; POEGIMA (3: 192) kas lehm on ennast juba kasinud?; PUHASTAMA (3: 206) '(ennast) puhastama, koristama (oma, lapse ninaalust, tuba, lauda, põrandat, ukseesist)'; PÕLlUVILJA KORISTUS (3: 401) vilja k [asima] 'vilja koristama'; vIIMA (4: 520) kasi siit minema hlv; kasin aga mõisterühmades KOKKUHOID (2: 24); KÕLbELINE (2: 195) 'kõlbeliselt puhas, karske, viisakas, mõõdukas'; MõõDUKAS (2: 1005) 'mõõtupidav, mõõdukas'; NõRK (2: 1180) ta on kasina kuulmisega; õige kasinad jäljed jäid lume sisse; PARAS (3: 60); PUHAS (3: 203) 'puhas, ennast hästi kasiv ja korralik'; TAGASIHOIDLIK (3: 1077); TEE (3: 1248) kasin tee 'veel väheselt sõidetud tee'; viIsAKus (4: 524) 'viisakas, korralik, karske'; vILETs (4: 535) 'mõõdukas, vähene, kehv'; vÄHENE (4: 671) 'vähene, väheselt esinev, väiksearvuline, vähemärgatav'; väıKE (4: 677). kasima tavalisemad paralleelverbid eesti regilauludes on sugema 'kammima, harjama', pesema, pühkima, vaalima 'pesema', lõunaeesti regilauludes ka põimama 'rukist lõikama, vilja koristama' (Eesti regilaulude andmebaas).

kasin esineb Mülleri jutlustes (1600-1606): se Neutzikene Maria [---] on väillus, puhas ninck kaßinas Neutzikene iehnut (vt Habicht jt 2000: 128). Seejärel on kasin ja sellest tuletatud kasinus 'kõlbeline puhtus, vooruslikkus, 
karskus; vähesus, nappus' järjekindlalt noteeritud eesti vanemas kirjasõnas ja leksikograafilistes allikates, tähistades kristliku kõlbluse olulisi arusaamu. kasima esmamaining leidub Heinrich Stahli 1638. aastal ilmunud teose „Handund Hausbuch" III osas: Erranis ehhitaket hend se Jssanda Jesusse Christusse kahs / ninck kassiket sedda iho (Habicht jt 2015: 143). Leksikograafiaallikaist noteerib verbi esimesena Heinrich Göseken: Mässigen [= end ohjeldama], kassima / hend kassinast piddama (Göseken 1660: 289).

kasima-perel on vasteid läänemeresoome lõunarühma keeltes. Salatsiliivist on teada adverb kašinest 'vähe / wenig', vrd ee kasinasti 'vähevõitu, napilt' (Winkler, Pajusalu 2009: 80), kuraliivist adjektiiv kaž̂in, kažìn 'kasin, puhas, korralik / keusch, reinlich, sauber, ordentlich' ja adverb kažînist 'puhtalt, korralikult / keusch, reinlich, sauber, ordentlich' (Kettunen 1938: 109b). Lauri Posti järgi on liivi kažîn eesti hilislaen, millele osutab sisekao puudumine (Posti 1942: 90). Üsna rikkalik keeleaines leidub vadjas: kasia 'kasida / ухаживать, приводить в порядок', kasiuta, kasivuta '(ennast) pesta, (ennast) kasida / обихаживаться', nt tšülpee veellä tšümmenellä, kasiu kahõssamalla $\mathrm{rl}$ 'vihtle ennast kümne veega, pese (kasi) ennast kaheksaga' (VKS 2: 109). Vadja kasi menemä! on võib-olla laen eesti väljendist kasi minema (VKS 2: 109; Tsvetkov 1995: 92). Kahtlemisi on eesti laenuks peetud ka üksnes Kukkusi murdest registreeritud adjektiivi kasina 'väikesevõitu / pienehkö': kasina se on niku pēnI, hän on muitez_лus _t'śI nōrikkI, a on kasinā kätẗ̈ 'ta on muidu kena noorik, aga on väikesevõitu' (VKKMS: 136).

Kirjaliku laenu juhtum on Christfrid Gananderi 1786. aastal ilmunud sõnaraamatu "Nytt Finskt Lexicon” 1. köites leiduvad kassina, -nan adj 'tuchtig, pudicus (kaino)', kassinasti adv 'tuchtigt, ärligt, pudice' (kassin, kassinaste, Ehst[onice]) (Ganander 1997: 280); sõna pärineb Hupeli sõnaraamatust, millele osutab vana kirjaviisi -ss- pro -s- (SSA 1: 324). Gustaf Reinvall oli samuti seisukohal, et soome keele rikastamine eesti sõnadega on soome leksikograafi ülesanne: tema 1826. aastal ilmunud soome-ladina-saksa sõnastikus „Suomalainen Sana-Kirja" esinevad Hupeli sõnaraamatust pärinevad ee Kassina ja kassinasti (vt ka Mägiste 1933: 370, 1956: 174).

Tegu on balti, sealjuures vanimasse kihistisse kuuluva sõnalaenuga. Oletatav laenualus on blt *kās-, mille jätkajad on ld kóšti (kóšia, kóšè) 'vedelikku puhastamiseks läbi riide, sõela vm vahendi kallama, kurnama (nt piima), kääritatud õlut sademe eemaldamiseks läbi kurna vaati valama, filtreerima; (tr, intr) läbi puhuma (tuul), tugevasti sadama, vihma kallama; läbi tungima (päikesekiired); sõnu aeglaselt ja vihaselt läbi kokkusurutud hammaste lausuma; läbi hammaste rüüpima, rüüpsima; (euf) kusema' (Lietuvių kalbos žodynas) ja lt kãst, kàst ( $k \bar{a} s ̌, ~ k a \bar{s} s$ ) 'vedelikku puhastamiseks läbi kurnama, filtreerima; keeduvett (nt kartulitelt) ära nõristama', alu kāst 'õlut laotama, s.o õlut läbi kurna vaati valama', kāsība 'ôlle laotamine, s.o käärinud õlle läbi kurna vaati valamine; lähinaabritele saadetud või koos nendega pidusemalt joodud õllelaotis; joogiohver'; kāsību kāsības dzert 'õllelaotist jooma, s.o esimest sõõmu hea õnne nimel jooma', kāsības laiks 'tagavarade kogumise, soetamise aeg' (ME 2: 204; Reḳēna 1998: sub kàst, sub pà̀rkàsas; Tezaurs); kãst 'tugevasti vihma sadama, valama, kallama; peksma, kolkima' (EH 1: 606). Läti murdeja kõnekeeles on $k \bar{a} s t$ segunenud verbiga kārst 'kraasima; kurnama (nt piima); keeduvett (nt kartulitelt) ära kallama, nõrutama; tugevasti sadama' (ME 2: 198; 
Tezaurs). Kazimieras Būga on balti verbid 1921. aastal sidunud läti adjektiividega kuošs 'kaunis, peen, läbipaistev, selge', kuoss 'selge, läbipaistev' (vt Būga 1959: 343), samal seisukohal on Vladimir Toporov (1980: 206-207); Ernst Fraenkel on seda etümoloogilist seost tõrjunud (LEW 1: 284). Balti sõnaperel ei ole selgeid etümoloogilisi seoseid väljaspool keelkonda (LEV 1: 389; ALEW 1: 517; Smoczyński 2016: 592-593). Võimalik etümoloogiline seos slaavi keelte pudrunimetusega *kāsiā (vrd nt vn каша 'puder' $\leftarrow$ *peeneks hõõrutud viljaterad' (vt Lietuvių kalbos etimologinio žodyno duomenų bazė) on ÈSSJa (9: 158-159) järgi formaalselt õnnestunud, kuid semantiliselt vähem veenev.

Läti verbi kāst pikk $\bar{a}$ on algbalti algupära. Leedu keeles on balti * $\bar{a}$ säilinud vaid vanaleedu tekstides ja osaliselt murdekeeles (Rudzite 1993: 141-142). Balti *-s- on läti keeles püsinud samuti paremini kui leedu keeles, kus blt ${ }^{*} s>\check{s}$ (peamiselt $r, k, i, u$ järel) (Rudzīte 1993: 276-277). Balti $* \bar{a}$ läänemeresoome substituut $a$ tõendab, et kõne all on vanema kihistise balti laen.

kasima on kohanenud $i$-liiteliste frekventatiiv- ja kontinuatiivverbidega (liite kohta vt Hakulinen 1968: 215); kasin on viimasest noomeniliitega $-(i) n \leftarrow{ }^{*}(i) n A$ (liite kohta vt Hakulinen 1968: 112-113) tuletatud adjektiiv. kasima-pere on läbi teinud mitmejärgulise semantilise arengu, ent säilitanud laenualuse semantilise põhimotiivi 'puhastama, puhastamise teel millestki soovimatust vabastama'.

Niisiis võib lõpetada nendinguga, et Mägiste algatatud etümoloogia on nüüd lõpuni viidud.

\section{Kirjandus}

ALEW 1-2 = Altlitauisches etymologisches Wörterbuch. (Studien zur historischvergleichenden Sprachwissenschaft 7.) Koost ja toim Wolfgang Hock, ElviraJūlia Bukevičiūtè, Christiane Schiller, Rainer Fecht, Anna Helene Feulner, Eugen Hill, Dagmar S. Wodko. Hamburg: Baar-Verlag, 2015.

B ū g a, Kazimieras 1959. Rinktiniai raštai II. Vilnius: Valstybinè politinès ir mokslinès literatūros leidykla.

EEW = Julius Mägiste, Estnisches etymologisches Wörterbuch 1-12. Helsinki: Finnisch-Ugrische Gesellschaft, 2000.

EH = Jānis Endzelīns, Edīte Hauzenberga, Papildinājumi un labojumi K. Mülenbacha Latviešu valodas vārdnīcai 1-2. Rīgā: Lettischen Kulturfonds / Grāmatu apgāds, 1934-1946.

EKMS = Andrus Saareste, Eesti keele mõisteline sõnaraamat 1-4. Dictionnaire analogique de la langue estonienne. Avec un index pourvu des traductions en français. (Eesti Teadusliku Seltsi Rootsis väljaanne 3.) Stockholm: Vaba Eesti, 1958-1963.

EKSS $=$ Eesti keele seletav sõnaraamat 1-6. „Eesti kirjakeele seletussõnaraamatu" 2., täiendatud ja parandatud trükk. Toim Margit Langemets, Mai Tiits, Tiia Valdre, Leidi Veskis, Ülle Viks, Piret Voll. Tallinn: Eesti Keele Sihtasutus, 2009.

EMS = Eesti murrete sõnaraamat I-. Tallinn: Eesti Keele Instituut 1994-.

ÈSSJa = Étimologičeskij slovar' slavjanskih jazykov. Praslavjanskij leksičeskij fond 1-. Peatoim O. N. Trubačev. Moskva: Nauka, 1974-. http://etymolog.ruslang.ru 
(25. I 2019). [Этимологический словарь славянских языков. Праславянский лексический фонд. Отв. ред. О. Н. Трубачев. Москва: Наука.]

Gan ander, Christfrid 1997. Nytt Finskt Lexicon. (Suomalaisen Kirjallisuuden Seuran toimituksia 676. Kotimaisten Kielten Tutkimuskeskuksen julkaisuja 95.) Alkuperäiskäsikirjoituksesta ja sen näköispainoksesta toimittanut Liisa Nuutinen. Helsinki: Suomalaisen Kirjallisuuden Seura, Kotimaisten Kielten Tutkimuskeskus.

Göseken, Heinrich 1660. Manuductio ad Linguam Oesthonicam. Anführung zur Öhstnischen Sprache. Reval: Gedruckt und verlegt von Adolph Simon / Gymnasij Buchdr.

Habicht, Külli, Kingi sepp, Valve-Liivi, Pirs o, Urve, Prillop, Külli 2000. Georg Mülleri jutluste sõnastik. (Tartu Ülikooli eesti keele õppetooli toimetised 12.) Toim Jaak Peebo. Tartu: Tartu Ülikool.

Habicht, Külli, Penjam, Pille, Prillop, Külli 2015. Heinrich Stahli tekstide sõnastik. Toim Valve-Liivi Kingisepp. Tartu: Tartu Ülikooli Kirjastus.

Haku lin e n, Lauri 1968. Suomen kielen rakenne ja kehitys. 3., korjattu ja lisätty painos. Helsinki: Otava.

Ka a le p, Heiki-Jaan, M u i s c h n ek, Kadri 2002. Eesti kirjakeele sagedussõnastik. Tartu: Tartu Ülikooli Kirjastus. http://www.cl.ut.ee/ressursid/sagedused/index. php?lang=et (25. I 2019).

Kettunen, Lauri 1938. Livisches Wörterbuch mit grammatischer Einleitung. (Lexica Societatis Fenno-Ugricae V.) Helsinki: Suomalais-Ugrilainen Seura.

LEV = Konstantīns Karulis, Latviešu etimoloǵijas vārdnīca 1-2. Rīga: Avots, 1992.

LEW = Ernst Fraenkel, Litauisches etymologisches Wörterbuch 1-2. Heidelberg: Carl Winter, Universitätsverlag, Göttingen: Vandenhoeck \& Ruprecht, 19621965.

ME = K. Mīlenbacha Latviešu valodas vārdnīca 1-4. Toim Jānis Endzelīns. Rīgā: Lettischen Bildungsministerium / Lettischen Kulturfonds, 1923-1932.

Mäg is te, Julius 1933. Mis on soomlased laenanud eesti keelest? - Eesti Kirjandus, nr 8, lk 368-377.

Mäg ist e, Julius 1956. Toonane eesti keele harrastaja Soomes. - Tulimuld, nr 4, lk 173-174.

Posti, Lauri 1942. Grundzüge der livischen Lautgeschichte. (Suomalais-Ugrilaisen Seuran toimituksia LXXXV.) Helsinki: Suomalais-Ugrilainen Seura.

Reḳēn a, Antoṇina 1998. Kalupes izloksnes vārdnīca 1-2. Rīga: Latviešu valodas institūts.

Rudzīte, Marta 1993. Latviešu valodas vēsturiskā fonētika. Rīga: Zvaigzne.

S moc zyński, Wojciech 2016. Słownik etymologiczny języka litewskiego. Wydanie drugie, poprawione i znacznie rozszerzone. Na prawach rękopisu. https:// rromanes.org/pub/alii/Smoczyński\%20W.\%20Słownik\%20etymologiczny\%20 języka\%20litewskiego.pdf (25. I 2019).

SSA = Suomen sanojen alkuperä. Etymologinen sanakirja 1-3. (Suomalaisen Kirjallisuuden Seuran toimituksia 556. Kotimaisten Kielten Tutkimuskeskuksen julkaisuja 36.) Peatoim Ulla-Maija Kulonen. Helsinki: Suomalaisen Kirjallisuuden Seura, Kotimaisten Kielten Tutkimuskeskus, 1992-2000.

T o p o r ov, Vladimir Nikolaevič 1980. Prusskij jazyk. Slovar' 3. Peatoim V. V. Ivanov. Moskva: Nauka. [Владимир Николаевич Топоров, Прусский язык. Словарь 3. Отв. ред. В. В. Иванов. Москва: Наука.] 
Tsvetk ov, Dmitri 1995. Vatjan kielen Joenperän murteen sanasto. (Lexica Societatis Fenno-Ugricae 25.) Toim Johanna Laakso. Helsinki: Suomalais-Ugrilainen Seura.

VKKMS = Vatjan kielen Kukkosin murteen sanakirja. (Lexica Societatis FennoUgricae XIX.) Ainekset kerännyt L. Posti, painokuntoon toimittanut S. Suhonen L. Postin avustamana. Helsinki: Suomalais-Ugrilainen Seura, 1980.

VKS $=$ Vadja keele sõnaraamat 1-7. Toim Elna Adler, Merle Leppik, Silja Grünberg. Tallinn: Eesti Keele Instituut, 1990-2011.

W i e d e m a n n, Ferdinand Johann 1973 [1893]. Eesti-saksa sõnaraamat. Estnischdeutsches Wörterbuch. Neljas, muutmata trükk teisest, Jakob Hurda redigeeritud väljaandest. Vierter unveränderter Druck nach der von Jakob Hurt redigierten Auflage. Tallinn: Valgus.

W in kl er, Eberhard, P aj u s a l u, Karl 2009. Salis-livisches Wörterbuch. (Linguistica Uralica. Supplementary Series 3.) Tallinn: Teaduste Akadeemia Kirjastus.

\section{Võrguväljaanded}

Eesti regilaulude andmebaas. http://www.folklore.ee/regilaul/andmebaas (25. I 2019).

Lietuvių kalbos etimologinio žodyno duomenų bazè. http://etimologija.baltnexus.lt (25. I 2019).

Lietuvių kalbos žodynas. www.lkz.lt (25. I 2019).

Tezaurs. http://www.tezaurs.lv (25. I 2019).

\section{Kasutatud keele- ja grammatikalühendid}

adj = adjektiiv; adv = adverb; blt = (alg)balti keel; ee = eesti keel; euf $=$ eufemism; intr = intransitiivne; ld = leedu keel; lms = läänemeresoome keeled; $\mathbf{l t}=$ läti keel; $\mathbf{r l}=$ rahvaluule; $\mathbf{t r}=$ transitiivne; $\mathbf{v n}=$ vene keel.

\section{Murded ja murrakud}

$\mathbf{e L}=$ lõunaeesti murdekeel; $\mathbf{e P}=$ põhjaeesti murdekeel; Juuru; $\mathbf{R}=$ kirderannikumurre.

Lembit Vaba (snd 1945), PhD, Läti Teaduste Akadeemia välisliige (Roosikrantsi 6, 10119 Tallinn), phorest45@gmail.com 


\section{An etymology accomplished: kasima and kasin}

Keywords: Estonian, Finnic languages, Baltic loanwords, lexical history

Although Julius Mägiste in his "Estnisches etymologisches Wörtebuch" has pointed out the Estonian word family of kasima as well as its Livonian and Votic counterparts as possible Baltic loans, he fails to mention the source word. This article accomplishes the etymology by suggesting *kās- as the possible Baltic etymon, some derived terms being, e.g. Lithuanian kóšti (kóšia, kóšè) 'to strain a liquid (e.g. milk) for purification, to pass fermented ale through a strainer to prevent sediment from getting into the barrel etc.' and Latvian $k \tilde{a} s t, k a ̀ s t ~(k \bar{a} \breve{s}, k \bar{a} s a)$ 'to strain a liquid for purification, to filter; to drain off the boiled water (e.g. from potatoes) etc.'

Lembit Vaba (b. 1945), PhD, Foreign Member of the Latvian Academy of Sciences (Roosikrantsi 6, 10119 Tallinn),phorest45@gmail.com 